\title{
Numerical Investigation of Different Airflow Schemes in a Real Operating Theatre
}

\author{
Carla Balocco ${ }^{1}$, Giuseppe Petrone ${ }^{2 *}$, Giuliano Cammarata ${ }^{2}$ \\ ${ }^{1}$ Department of Industrial Engineering, University of Firenze, Firenze, Italy \\ ${ }^{2}$ Department of Industrial Engineering, University of Catania, Catania, Italy \\ Email: "gpetrone@dii.unict.it
}

Received 30 December 2014; accepted 5 February 2015; published 11 February 2015

Copyright (C) 2015 by authors and Scientific Research Publishing Inc.

This work is licensed under the Creative Commons Attribution International License (CC BY). http://creativecommons.org/licenses/by/4.0/

(c) (i) Open Access

\begin{abstract}
A study on performances of different ventilation schemes provided by vertical and horizontal unidirectional air flow was carried out in a standard orthopaedic operating theatre (OT). Starting from our previous studies of a real OT under operating use conditions, in this research different air flow configurations, considering some air curtain solutions on the ceiling and at the sliding door always assumed to be open as a basic boundary condition, were investigated by numerical simulations. Indoor air quality (IAQ) indexes and thermal comfort parameters, deduced from simulation results were calculated and discussed referring to the best performance and efficacy between the air flow schemes to contrast the incorrect use conditions of the OT. Referring to the studied schemes, the reciprocal comparison emphasizes that a successful outcome in preventing surgical site infection can depend as much on resolving human factors (i.e. operational use conditions, door opening/closing), as on overcoming physical and technical obstacles.
\end{abstract}

\section{Keywords}

Real Operating Theatre, Ventilation Schemes, Air Curtain, IAQ, Thermal Comfort

\section{Introduction}

The design of any OT is a complex task and is conditioned by high indoor requirements of microclimate (mainly due to the stability of air temperature, relative humidity, scheme of pressures, mean velocity) and air quality.

All the present standards provide important and tight threshold limit values of microclimatic parameters, contaminants concentration and IAQ levels, for the OT design [1]-[11]. Therefore, there is a great deal of research on ventilation system efficiency for providing the most effective airflow pattern for contaminant removal

\footnotetext{
${ }^{*}$ Corresponding author.
}

How to cite this paper: Balocco, C., Petrone, G. and Cammarata, G. (2015) Numerical Investigation of Different Airflow Schemes in a Real Operating Theatre. J. Biomedical Science and Engineering, 8, 73-89. 
(microorganisms i.e. fungi, bacteria, viruses; chemical i.e. waste anesthetic gases, $\mathrm{CO}_{2}$ and particulate matter) and assuring the control of surgical site infection risk. The goal of any air distribution system is to protect the patient and surgical staff from cross-infection and at the same time assuring occupant comfort: but it has also been found that thermal control for occupant comfort can affect sepsis control within the three zones (occupied zone, breathing zone and perimetral zone) of the OT. Ventilation system performance in OTs can be directly and/or indirectly evaluated, with passive and active air sampling techniques, in the first case, and real simulations of particle/bacteria transport using fixed sources or tracer gases when the OT is not in operating conditions, in the second one. The greatest advantage of the latter method, is due to the source strength fixed position, so that ventilation system performance variations can be directly evaluated by the measured concentration differences.

Some authors have studied the effectiveness of ventilation systems and airborne bacteria removal due to the HVAC plant, in particular, in the surgical critical zone (operation table and instrument tables). Experimental measures carried out in a test chamber reproducing a real standard OT are based on the use of gas sources placed on the floor in proximity of the operating area [12]. CFD modelling and simulation are widely applied for providing useful indications on proper indoor microclimate conditions and IAQ, that are prerequisites for securing a safe and adequate environment for any OT [13]. Usually, three-dimensional time-dependent CFD models are developed to assess the airflow patterns, air velocity and temperature distribution due to laminar unidirectional (vertical downward) air flows [14], in other cases to turbulent air flows and also to the air curtains so as to achieve IAQ and optimal air asepsis [15] [16].

Other authors have used CFD for a three dimensional analysis of thermal comfort and contaminant removal inside hospitals: checking model validity by experimental literature evidence and data comparison, they calculated the predicted mean vote (PMV), contaminant removal effectiveness (CRE) and mean contaminant concentration in the breathing zone by transient simulation results, in order to assess HVAC system efficiency. They investigated the effect of horizontal location of supply and exhaust grilles also for maintaining adequate comfort conditions for patients and surgical staff [17] [18]. In much of the literature computational fluid dynamics (CFD) simulation has been used to assess colony forming unit (cfu) dispersion and evaluate air flow distribution effectiveness in real OTs [19] [20] and in other more specific research the influence of periodic bending movement of the medical staff combined with bacteria carrying particle distribution on the airflow field and temperature distribution have been investigated [20].

Most of these studies consider correct use, on-design operational conditions of OTs. Some analyses have been proposed concerning moving object effects on the airflow inside OTs [21] [22]. In the above papers the moving mesh approach is applied in order to manage the fluid-solid interface during transient simulations. An impressive study concerning the influence of movements on contaminant transport in an OT has been published by [23], using smoke visualization and numerical simulations to estimate the increase of contamination potential risk due to moving medical staff. In a recent study, an experimental and numerical investigation on the airflow patterns and thermal field in a real OT has been presented [24]. Different scenarios representative of "at rest" and "operational/effective use" conditions were measured and simulated, then numerical models successfully validated against experimental data. Simulations were developed to investigate the air flow and climate assessment in the real OT studied, considering real events such as surgical staff movements, and sliding door opening/closing phases [24]. In particular, the adopted procedure for simulating the "moving objects" inside the room and their influence on the air flow pattern, has been explained in detail in previous studies by the same authors [25] [26]. A recent study based on experimental measurements and CFD simulation shows the efficacy of different ventilation systems in removing bacteria and particles using adducted return strategy to induce air flow from clean to less clean zones [27]. These authors propose a new design that changes the normal corridor return, without an air return duct, with an exhaust air duct extracting exhaust air from inside the cubicle towards the open area outside the hospital. In the literature there is not much that addresses the analysis of the efficiency of a ventilation system in an OT, equipped with ante-chamber and/or air locking system for guaranteeing air pressure difference, indoor microclimatic conditions and IAQ, minimizing the air flow inlet from non-clean zones to the OT. A few authors have dealt with the efficiency of air curtain application for producing a vertical downward air curtain around the laminar diffuser using experimental data and CFD modelling of the studied OT, because most of the work on this subject deals with different applications [28]-[32].

In a recent paper linear slot diffusers were used to create a vertical downward air curtain around the ceiling unidirectional flow diffuser towards low-level exhaust grilles, to avoid the in-ward flow under the unidirectional diffuser. The authors demonstrated that a clear correlation between the unidirectional flow and air curtain flow 
rates and concentration cannot be assumed and in particular, that following the usual manufacturer specifications for sizing the air curtain and laminar flow diffusers, may not necessarily result in better indoor microclimate and IAQ conditions [33]. In the most recent literature, the assessment of ventilation efficiency in OTs, including air flow distribution under different configurations and different positions of diffuser supply velocity, is studied by applying CFD simulation and full-scale experimental investigations [34] [35].

The wide ranging research and the most impressive literature on this subject have demonstrated the influence of different ventilation system solutions on the internal microclimatic conditions of OTs. In particular, much research, paying specific attention to modelling particles and contaminant diffusion, has highlighted that the real operating use conditions of the OTs, e.g. the door opening and closing and medical staff movements, cause important perturbations on the air velocity and temperature distribution compared to the design conditions and deflection from the suggested parameter values ensuring microclimatic, thermal comfort and IAQ state [20] [23] [36].

Following the above literature approaches and analyzing the fundamental literature results, we are interested in investigating which scheme of the ventilation system inside the OT (i.e. dimensions and position of the inlet and outlet air diffusers) can minimize the critical and risk conditions caused by real operational use conditions. From a well-known starting phase, concerning our previous study of a real OT under operating use conditions, developed through an experimental and numerical modelling approach [25] [37], in this research we analyzed different configurations of the present ventilation scheme. In particular, our research starts from the studies of a real OT, investigated by experimental measurements and CDF simulations: numerical models in use were first validated against experimental data collected during monitoring campaigns. Starting from the validated model, some crucial indexes on the IAQ, ventilation efficiency and thermal comfort parameters, deduced from the numerical results of the CFD simulations, were calculated and discussed for each of the new proposed ventilation schemes. The performance of each ventilation solution was investigated, assuming the sliding door to be open as a basic boundary condition.

The aim of our present research is the study of ventilation system performance using different air flow distribution schemes, which are produced by combining each of the two basic air flows (vertical unidirectional and horizontal unidirectional) with air curtain solutions on the ceiling and at the sliding door.

\section{The Investigated Ventilation Schemes for the OT}

Our research starts from the validated numerical model built up with experimental and numerical results obtained from the OT simulation results under real use conditions, presented in recent studies by the authors [24] [37]. In these articles the authors showed the robustness and validity of their models by comparison between experimental and numerical results: the influence of mesh refinement on results was also investigated in order to assure mesh independent results, and experimental and numerical results concerning ventilation patterns, $\mathrm{CO}_{2}$ concentration and particle diffusion in the OT, were discussed [24].

The validated model of the studied real orthopaedic OT, labelled from now on "M_real", refers to a room geometry that was outlined by a rectangular-shaped room with smoothed corners, a $43 \mathrm{~m}^{2}$ base area and $120 \mathrm{~m}^{3}$ volume (Figure 1). The room is equipped with an operating bed and lighting system made up of three joined arms, each one holding three lamps and with a sliding door that connects the room to an entry corridor (Figure 1). In this figure the locations of the staff members, surgical lamps and equipment for the operating table, defined in the model are shown. Two rectangular supply ceiling diffusers $\left(0.56 \mathrm{~m}^{2}\right.$ surface each one) are located in the central zone of the ceiling, that strengthen the unidirectional flow. Two groups of 14 conical outgoing grilles (cross-section of $0.0128 \mathrm{~m}^{2}$ ) are arranged over two of the opposite four walls corresponding to the smoothed corners of the room and allow the internal air to outflow. Referring to ANSI/ASHRAE Standard 62.1-2004 and ANSI/ASHRAE Standard 55-2004, the global OT air-volume (TV) was divided into 3 zones, labelled from now on as Breathing Zone (BZ, highlighted in green in Figure 2), Occupied Zone (OZ, highlighted in green plus orange in Figure 2) and Peripheral Zone (PZ, corresponding to TV-OZ). This allowed the computation of air quality and thermal comfort indexes referring to each one of the mentioned zones. Six different additional configurations of the ventilation scheme were studied starting from the initial one concerning real operating use conditions (M_real).

For these six ventilation schemes a constant air flow rate of 25 fresh air changes per hour was assumed, because this is the optimal choice obtained by comparison between suggested values by present Italian and International 


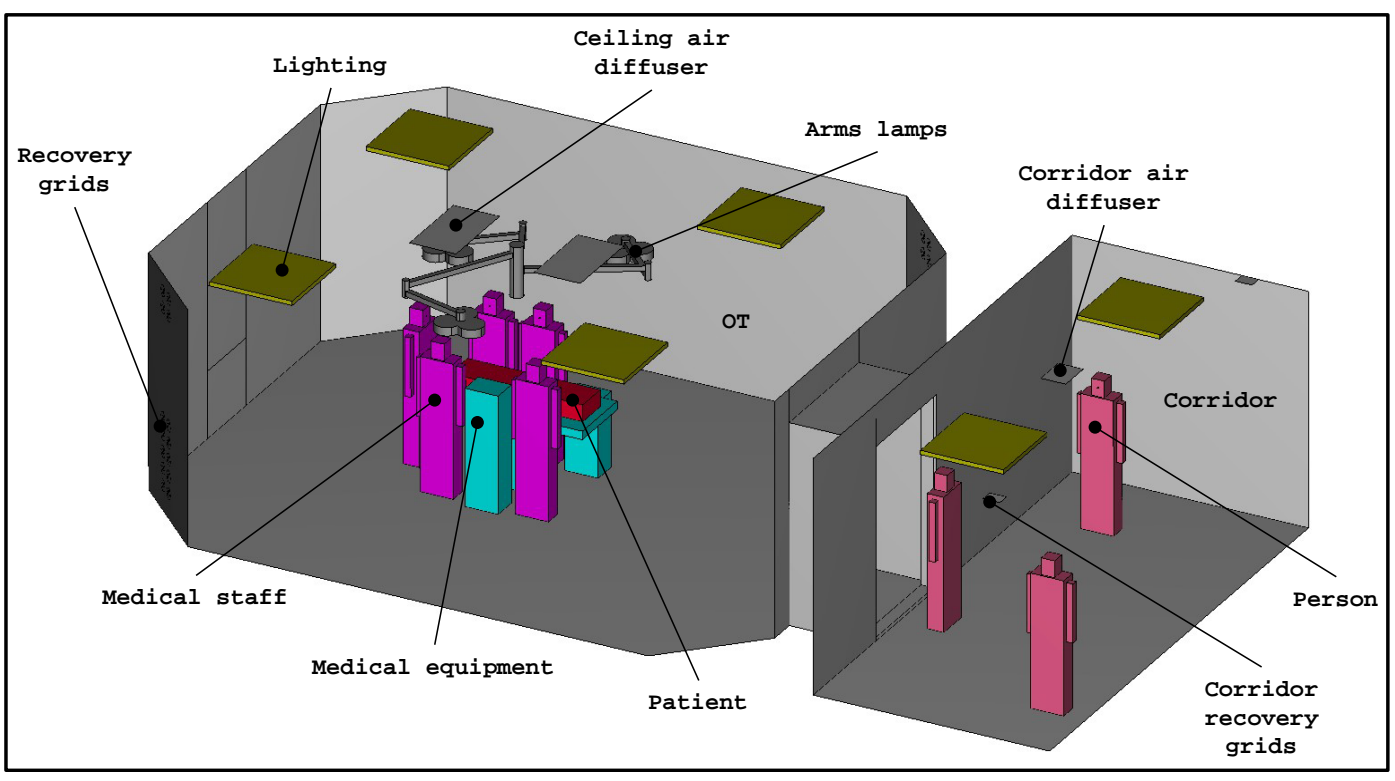

Figure 1. Geometry of the studied system (M_real).

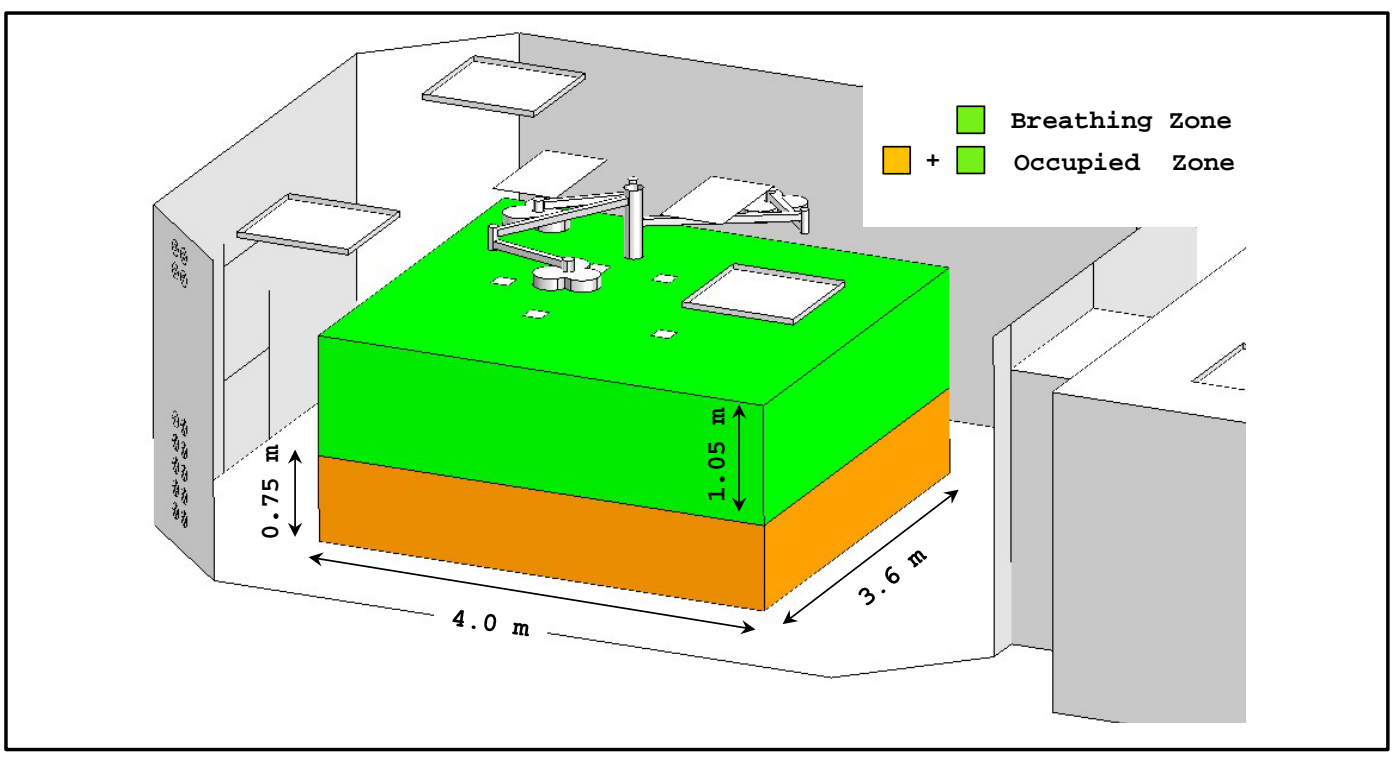

Figure 2. Graphical representation of the Breathing (green) and Occupied (green plus orange) zone.

standards for pressurization and ultra-clean ventilation of orthopaedic OTs [1]-[9] [11] [38]. Moreover, the six ventilation schemes differ from each other in dimension and position of the air supply and return diffusers inside the studied OT. The proposed ventilation schemes were investigated combining the following basic elements: different configurations of air inlet components of the air curtain typology, located at the ceiling air supply diffusers and at the sliding door, two basic air flows, unidirectional-vertical and unidirectional horizontal, for the proposed ventilation schemes, different dimension and position of the air return grilles, these last mainly located near the sliding door and/or at the corners of the room. Very briefly, the following ventilation scheme modifications were proposed:

- OT model with air supply (unidirectional vertical flow) and return scheme coinciding with the M_real but with one air curtain with two return grilles at the sliding door, M_1;

- OT model with air supply (unidirectional vertical flow) and return scheme coinciding with the M_real but with two air curtains at the ceiling supply diffuser along the two sides of the operating table, M_2; 
- OT model with only one central air supply ceiling diffuser (unidirectional vertical flow), four air return grilles located down and one air curtain with two return grilles at the sliding door, M_3;

- OT model with only one central air supply ceiling diffuser (unidirectional vertical flow), four air return grilles located down, four perimetral air curtains located on the ceiling corresponding to the occupied zone, M_4;

- OT model with one lateral air supply wall diffuser (unidirectional horizontal flow) with four air return grilles located at the bottom and top of the opposite wall and one air curtain with two return grilles at the sliding door, M_5;

- OT model with one lateral air supply wall diffuser (unidirectional horizontal flow) with four air return grilles located at the bottom and top of the opposite wall and without air curtain with two return grilles at the sliding door, M_6.

Figure 3 shows the geometric elements used as inlet (in blue) and return (in red) sections for the previously listed configurations. For all the schemes, the total air flow rate was considered constant and equal to 3000 $\mathrm{m}^{3} \cdot \mathrm{h}^{-1}$ of fresh air (25 ACH), distributed between the air supply diffusers and different air curtain systems. This choice is related to the aim of our investigation, mainly consisting in assessing which ventilation scheme assures the better performance in IAQ and thermal comfort, keeping constant the total amount of incoming fresh air, the sliding door position (open) and the corridor conditions. The relative rates of fresh air supplied to the OT by the different diffusers (located at ceiling or wall) and air curtains are given in Table 1 for the studied configurations. This table also shows the air velocity at inlet sections and inlet and return grille surfaces.

\section{Numerical Solution}

Simulations were carried out by commercial software allowing multi-physical analyses through solutions of the

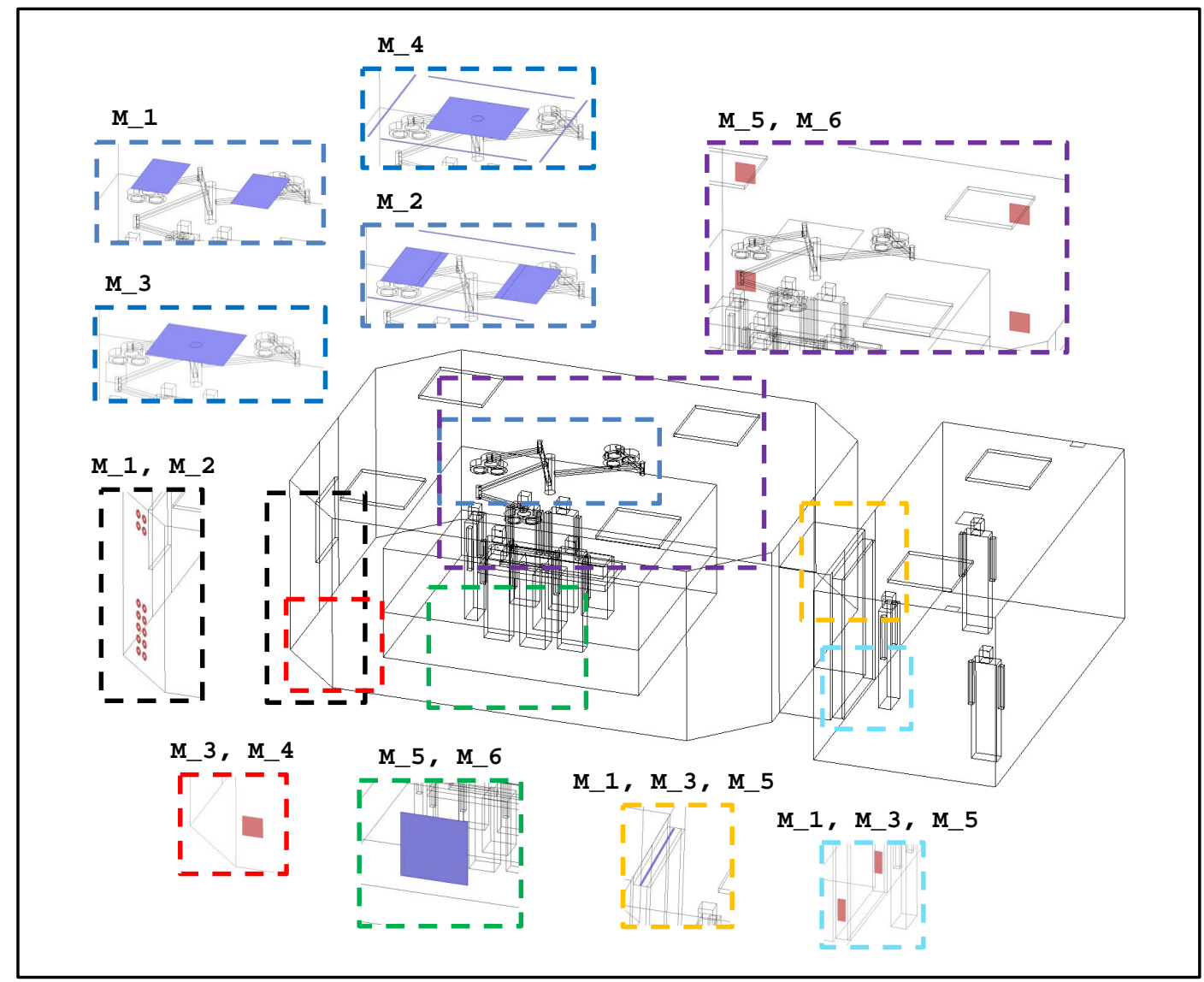

Figure 3. Inlet (blue) and return (red) sections of the ventilating air diffusers for the different ventilation schemes. 
Table 1. Ventilation air flow rate and supplying/recovery grille surfaces for each ventilation scheme.

\begin{tabular}{cccccccccccc}
\hline & \multicolumn{2}{c}{$\begin{array}{c}\text { Rate of } \\
\text { supply air }\end{array}$} & $\begin{array}{c}\text { Total supply } \\
\text { surface }\end{array}$ & $\begin{array}{c}\text { Air diffuser } \\
\text { surface }\end{array}$ & $\begin{array}{c}\text { Air curtain } \\
\text { surface }\end{array}$ & $\begin{array}{c}\text { Air velocity } \\
\text { at diffuser }\end{array}$ & $\begin{array}{c}\text { Air velocity } \\
\text { at curtain }\end{array}$ & $\begin{array}{c}\text { Total recovery } \\
\text { surface }\end{array}$ & $\begin{array}{c}\text { Recovery } \\
\text { surface }\end{array}$ & $\begin{array}{c}\text { Recovery surface } \\
\text { (curtain) }\end{array}$ \\
\cline { 2 - 11 } & Diffuser & Curtain & {$\left[\mathrm{m}^{2}\right]$} & {$\left[\mathrm{m}^{2}\right]$} & {$\left[\mathrm{m}^{2}\right]$} & {$[\mathrm{m} / \mathrm{s}]$} & {$[\mathrm{m} / \mathrm{s}]$} & {$\left[\mathrm{m}^{2}\right]$} & {$\left[\mathrm{m}^{2}\right]$} & {$\left[\mathrm{m}^{2}\right]$} \\
\hline M_1 & $90 \%$ & $10 \%$ & 1.147 & 1.120 & 0.027 & 0.67 & 3.06 & 0.429 & 0.369 & 0.06 \\
M_2 & $80 \%$ & $20 \%$ & 1.202 & 1.120 & 0.082 & 0.60 & 2.02 & 0.369 & 0.369 & 0 \\
M_3 & $90 \%$ & $10 \%$ & 1.147 & 1.120 & 0.027 & 0.67 & 3.06 & 0.408 & 0.348 & 0.06 & 0 \\
M_4 & $60 \%$ & $40 \%$ & 1.281 & 1.120 & 0.161 & 0.45 & 2.07 & 0.348 & 0.348 & 0.06 \\
M_5 & $90 \%$ & $10 \%$ & 1.147 & 1.120 & 0.027 & 0.67 & 3.06 & 0.408 & 0.348 & 0.06 \\
M_6 & $100 \%$ & $0 \%$ & 1.120 & 1.120 & 0 & 0.74 & 0.00 & 0.348 & 0.348 & 0 \\
\hline
\end{tabular}

related governing equations by a Finite Element approach [39]. In particular, our analyses provided solutions for the following variables: air velocity $(\boldsymbol{U})$ air pressure $(p)$, temperature $(T)$, carbon-dioxide concentration in air $\left(\mathrm{CO}_{2}\right)$, mean age of air $(\tau)$ and CFU concentration in air (CFU). The basic formulation of the partial differential equation formulation (PDE) used for computations is reported below:

$$
\frac{\partial(\rho \phi)}{\partial t}+\nabla \cdot(\rho \phi \boldsymbol{U})=\nabla \cdot(\Gamma \nabla \phi)+\Lambda
$$

where $\rho$ is the fluid density, $\boldsymbol{U}$ is the velocity vector, $\Gamma$ is the diffusion coefficient and $\Lambda$ is the source term. For fluid-dynamical analysis we used a RANS approach considering the fluid Newtonian and the flow incompressible. Turbulence was solved by applying a standard two-equation $(k-\varepsilon)$ closure scheme [40] [41]. For each governing equation, the analytical formulation of the different symbols used in the generic Equation (1) is reported in Table 2. Values of physical properties for materials and objects used in the numerical models are listed in Table 3. Independently from the specific ventilation scheme, at the inlet sections for air incoming into the system we applied the following boundary conditions: constant velocity, as defined in Table 1, for the OT and assumed equal to $0.66 \mathrm{~m} / \mathrm{s}$ for the corridor diffusers (6 ACH). Turbulence intensity at inlet was set equal to $5 \%$. Values of the other first-type boundary conditions applied at the inlet sections are reported in Table 4. For breathing modelling, we assumed a sinusoidal trend for inhaled/expired air and for $\mathrm{CO}_{2}$ emission rate into the room. In steady state simulations, we used the corresponding root mean square (RMS) values as magnitude for air velocity and $\mathrm{CO}_{2}$ mass flow rate at the nostrils of the medical staff, patient and persons standing in the corridor. Table 5 shows the set of parameters used to simulate people presence, in terms of breathing, heat production, $\mathrm{CO}_{2}$ and $\mathrm{CFU}$ emission in the indoor environment.

Outflow conditions were considered for all the dependent variables at the recovery grids. At each solid/fluid interface, logarithmic wall functions were applied to the near wall airflow, that was considered parallel to the wall and being in a wall offset equal to one hundred viscous units. Turbulent production was assumed to equal dissipation at walls. For the remaining dependent variables impermeable/insulation conditions at solid walls were assumed. We used a non-uniform and non-structured computational mesh made up of the second order tetrahedral elements. Steady solutions of discrete equations were carried-out by applying an iterative dumped Newton-Raphson scheme [42] based on the discretized PDE linearization by a first-order Taylor expansion. Algebraic systems of equations coming from differential operator discretization were solved by a PARDISO package, a direct solver particularly efficient for solving unsymmetrical sparse matrixes by a LU decomposition method. The convergence criterion was set to $1 \mathrm{E}-5$. Time integration of governing equations for transient simulations was performed by applying an Implicit Differential-Algebraic (IDA) solver [43] which uses the variableorder and variable-step-size of Backward Differentiation Formulas (BDF). Because the time-marching scheme is implicit, a nonlinear system of equations must be solved at each time step. The above-mentioned Newton algorithm was exploited to solve this nonlinear system of equations. All computations were carried-out on a workstation with two 64-bit 6-core/12-thread processors speeding up to $2.3 \mathrm{GHz}$ of frequency and handling $128 \mathrm{~GB}$ of RAM. 
Table 2. Formulation of variables and parameters appearing in Equation (1).

\begin{tabular}{cccc}
\hline Equation & $\phi$ & $\Gamma$ & $\Lambda$ \\
Continuity & 1 & 0 & 0 \\
Momentum & $\boldsymbol{U}$ & $\mu+\mu_{T}$ & $-\nabla p+\boldsymbol{F}_{g}$ \\
Turbulent kinetic energy & $k$ & $\mu+\frac{\mu_{T}}{\sigma_{k}}$ & $\frac{1}{2} \mu_{T}\left[\nabla \boldsymbol{U}+(\nabla \boldsymbol{U})^{\mathrm{T}}\right]^{2}-\rho \varepsilon$ \\
Dissipation rate of kinetic energy & $\varepsilon$ & $\mu+\frac{\mu_{T}}{\sigma_{\varepsilon}}$ & $\frac{1}{2} C_{\varepsilon 1} \frac{\varepsilon}{k} \mu_{T}\left[\nabla \boldsymbol{U}+(\nabla \boldsymbol{U})^{\mathrm{T}}\right]^{2}-\rho C_{\varepsilon 2} \frac{\varepsilon^{2}}{k}$ \\
Energy & $T$ & $\frac{\lambda}{C_{p}}$ & $\frac{Q}{C_{p}}$ \\
Mean age of air & $\tau$ & $\Upsilon$ & $\rho$ \\
$\mathrm{CO}_{2}$ concentration & $\mathrm{CO}_{2}$ & $\rho D_{\mathrm{CO}}$ & $\rho$ \\
$\mathrm{CFU}$ concentration & $\mathrm{CFU}$ & $\rho D_{\mathrm{CFU}}$ & $\rho$ \\
\hline
\end{tabular}

Table 3. Physical properties of materials used in the numerical models.

\begin{tabular}{|c|c|c|c|c|}
\hline \multirow{2}{*}{ Material } & $\rho$ & $\eta$ & $\lambda$ & $C_{p}$ \\
\hline & {$\left[\mathrm{kg} / \mathrm{m}^{3}\right]$} & {$[\mathrm{Pa} \cdot \mathrm{s}]$} & {$[\mathrm{W} /(\mathrm{m} \cdot \mathrm{K})]$} & {$[\mathrm{J} /(\mathrm{kg} \cdot \mathrm{K})]$} \\
\hline Glass (window, lamp) & 2500 & - & 1.00 & 800 \\
\hline Aluminium (operating table, electro-medical case, surgical lamp) & 2700 & - & 160 & 900 \\
\hline Medical staff, patient, persons (in the corridor) & 950 & - & 0.62 & 4180 \\
\hline Air & $p /(R T)$ & $2 \mathrm{E}-5$ & 0.04 & 1004 \\
\hline
\end{tabular}

Table 4. Values of the dependent scalar variables at the inlet boundaries.

\begin{tabular}{ccccc} 
& Temperature & $\mathrm{CO}_{2}$ concentration & $\tau$ & $\mathrm{CFU}$ \\
\cline { 2 - 5 } & {$\left[{ }^{\circ} \mathrm{C}\right]$} & {$[\mathrm{ppm}]$} & {$[\mathrm{s}]$} & 0 \\
OT & 18 & 335 & 0 & 0.5 \\
Corridor & 24 & 450 & 0 & 250 \\
\hline
\end{tabular}

Table 5. Parameter values used in the numerical models for people presence simulation.

\begin{tabular}{|c|c|c|c|c|c|c|}
\hline & $\begin{array}{l}\text { Air flow rate } \\
\text { from nostril }\end{array}$ & $\begin{array}{l}\text { Nostril air velocity } \\
\text { (RMS value) }\end{array}$ & $\mathrm{CO}_{2}$ emission & $\begin{array}{c}\mathrm{CO}_{2} \text { flux from } \\
\text { nostril (RMS value) }\end{array}$ & Metabolic heat & CFU emission \\
\hline & {$[\mathrm{l} / \mathrm{h}]$} & {$[\mathrm{m} / \mathrm{s}]$} & {$[\mathrm{l} / \mathrm{h}]$} & {$\left[\mathrm{mol} /\left(\mathrm{m}^{2} \mathrm{~s}\right)\right]$} & {$[\mathrm{W}]$} & [CFU/s] \\
\hline Medical staff & 2000 & 1.964 & 80 & 2.143 & 131.9 & 3 \\
\hline Patient & 300 & 0.295 & 12 & 0.321 & 96.6 & 0 \\
\hline Persons (corridor) & 500 & 0.491 & 20 & 0.536 & 112.3 & 6 \\
\hline
\end{tabular}

\section{Results}

Simulations were computed under real operational conditions of the OT and with the above proposed ventilation solutions. Results are provided in the following sections: the first one is related to the air flow patterns and microclimatic parameter distribution; the second one concerns the air quality and comfort indexes. Then, a discussion section follows. 


\subsection{Airflow and Temperature Distribution}

From the airflow simulations different flow patterns were highlighted depending on the air supply and exhaust outlet grille location., Figure 4 shows the air velocity field in a horizontal slice of the OT obtained for the studied cases. M_1 and M_3 provide higher air velocity values in the zone below the ceiling supply diffuser and at the door equipped with an air curtain, although more uniformly distributed in M_3 at the BZ and OZ. In particular, in the PZ the velocity field provides the lowest air velocity at the surgical site with extreme limit values from $0.05 \mathrm{~m} / \mathrm{s}$ to the maximum of $0.1-0.15 \mathrm{~m} / \mathrm{s}$. Results obtained for M_4 indicate that the comfort level in the $\mathrm{TV}$, due to uniform air velocity distribution, and the air flow performance are satisfactory with a resulting air washing effect particularly efficient at the operation table, but also in the BZ and OZ. The ventilation scheme of M_4 highlights the fact that a global wider air supply surface is better for contaminant control and guarantees the absence of an air flow short circuit between the sole air supply diffuser, delimited by four perimetral air curtains, and high level outlets. The air inlet diffuser in the center of the ceiling, marked by air curtain location, provide an effective clean zone in the room. Due to different ventilation schemes, results of M_5 and M_6 models show a specific air motion field: the air washing effect is connected to the horizontal air flow performances and then to the resulting air flow displacement. This condition is even more evident for the M_5 ventilation scheme that is also equipped by the air curtain at the door zone. Figure 4 shows the air flow dragging effect due to the door equipped with the air curtain (M_1, M_3) with a local air velocity increase, reaching mean values of 0.2 $0.23 \mathrm{~m} / \mathrm{s}$. In M_2 the vertical and sharp direction of the air flow is more evident due to the two symmetrical

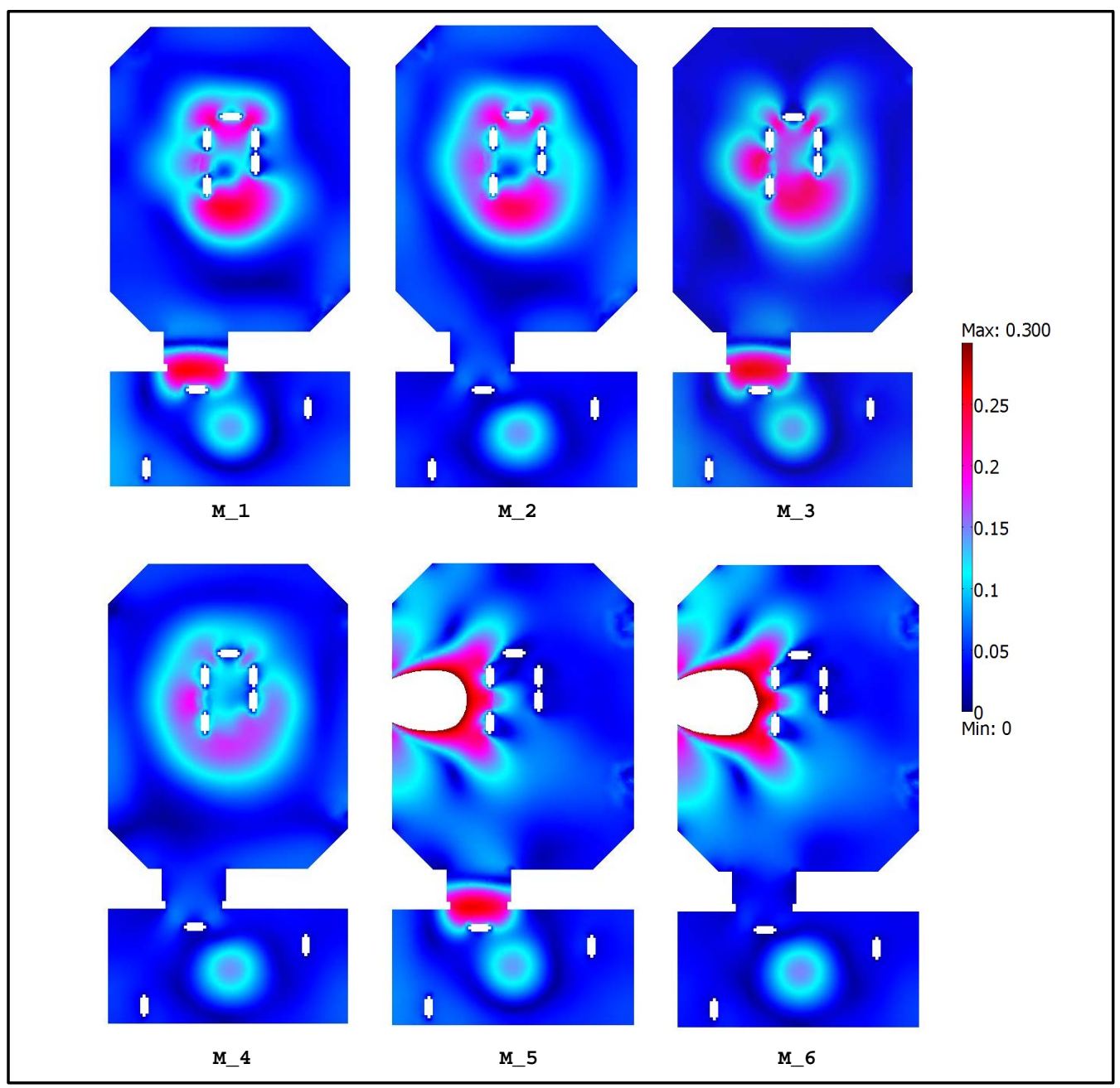

Figure 4. Air velocity field on a horizontal slide (1.4 $\mathrm{m}$ from the floor) for the different ventilation schemes obtained from the six models (from $M \_1$ to $\left.M \_6\right)$. 
supply diffusers and their lateral air curtains: in the central zone, defined by the BZ and OZ, the velocity field is more uniform and inside the PZ and TV guarantees an effective air washing effect, because it is not disturbed by the local flow turbulences at the door induced by the air curtain. The ventilation solution of M_4 shows a uniform air velocity distribution, produced by the vertical downward flow patterns at the whole microenvironment zone (i.e. surgical site) and the connected confinement effect, due to the four perimetral air curtains, of the air supply in the central zone of the room (BZ and OZ). In this ventilation solution the downward unidirectional flow results in an effective washing effect against the local $\mathrm{CO}_{2}$ concentration, thermal plume due to surgical lamps, and the total heat released by people. Analyzing all the six models results from the air motion field and velocity distribution points of view, the basic effect can be noted due to the unidirectional air flow (both vertical and horizontal) for leading to a low turbulence downward air displacement in all the OT zones. The different location around the $\mathrm{PZ}$ of the air recovery grilles connected to the different ventilation solutions, guarantees the exhaust air discharge through them and a piston effect, so that the air velocity at the room centre is always about $0.05 \mathrm{~m} / \mathrm{s}$. All the investigated ventilation schemes, including the two main unidirectional air flow configurations (vertical and horizontal) ensure only a single transit towards the surgical area from the ceiling and/or vertical wall (respectively from M_1 to M_4 and/or M_5 and M_6), but also that, if there is a solid object (e.g. surgical lamp and operation table and equipment tables and surgical staff) the air flow goes round it and then the unidirectional air flow pattern is distorted only in the immediate surroundings of the object itself. In particular, the ventilation schemes including air curtains at the zone of the sliding door (M_1, M_3 and M_5) seem to provide a less isolation effect of the OT microenvironment from the adjacent corridor zone, due to local air recirculation and turbulence phenomena combined with the air flow distribution induced by the conventional inlet diffusers of the corridor. This result can also be found in thermally comfortable OT conditions analyzing the PPD and comparing the ADPI index results, as presented in the following section. As a matter of fact, the ventilation scheme layout and design, especially of M_2 and more clearly in M_4 and M_6, indicates specific velocity field characteristics and performances: the disturbance effect to the air flow due to form, dimension and localization of surgical lamps and to the thermal plume around the surgical staff, does not intrude on the clean air near the patient.

The unidirectional air flow combined with the high supply rate to the room, guarantees the coldest air penetration to the floor and the washing effect in $\mathrm{BZ}$ and $\mathrm{OZ}$ maintenance. Similarly to the air flow assessment results, thermal effects were investigated. Microclimatic parameter assessment, $\mathrm{CO}_{2}$ concentration and the mean air age, were also directly obtained from simulation results. Results carried out by simulations of all the ventilation schemes, at the same condition of high inflow rate, show that optimal air distribution and thermal performance effects depend on larger inlet area and uniform inlet velocity profiles provided by extract outlet grille position and surface. The air temperature distribution results of $M \_2$ and $M \_3$ and also of $M \_1$, are comparable and show compliance with thermal requirements at the operation table, especially in the BZ (Figure 5). The ventilation scheme considered in M_4 produces the best results in terms of air temperature distribution uniformity in the BZ, OZ and TV. The presence of the air curtain at the sliding door (for all the models it was always considered open) seems to produce a dragging out effect with short -circuit particularly when the air supply diffusers are not symmetrical in respect to the BZ and OZ (M_1) but also when the sole ceiling supply diffuser, equipped with two lateral air curtains, is present, and causes the air flow confinement with imposed vertical direction to the operation bed (M_3).

As a consequence, the air temperature distribution is not uniform for $\mathrm{M} \_1$ and $\mathrm{M} \_3$ models, though temperature values around $22^{\circ} \mathrm{C}-24^{\circ} \mathrm{C}$ at the operation table could be maintained. This happens even when in the PZ, in particular at the end of the room on the opposite side of the zone with sliding door provided by the air curtain, the air temperature is higher and beyond thermal comfort conditions. The M_4 ventilation scheme produces the best results for the air temperature distribution inside the TV, and in particular in the BZ and OZ (Figure 5). It must be pointed out, that all the investigated ventilation solutions, from $M \_1$ to $M \_4$, consider the air supply unidirectional vertical flow. Both models, M_5 and M_6, defined by unidirectional horizontal air flow, respectively with and without the air curtain at the door, provide a good air temperature distribution in the $\mathrm{BZ}$ and $\mathrm{OZ}$, but less thermal uniformity in the PZ and globally in TV. In particular, temperature distribution in the PZ for both M_5 and M_6 models is mostly affected by horizontal air flow displacement.

\subsection{Indoor Air Quality and Comfort Indexes}

Referring to simulation results on air temperature and velocity distribution (Figure 4 and Figure 6), $\mathrm{CO}_{2}$ and 


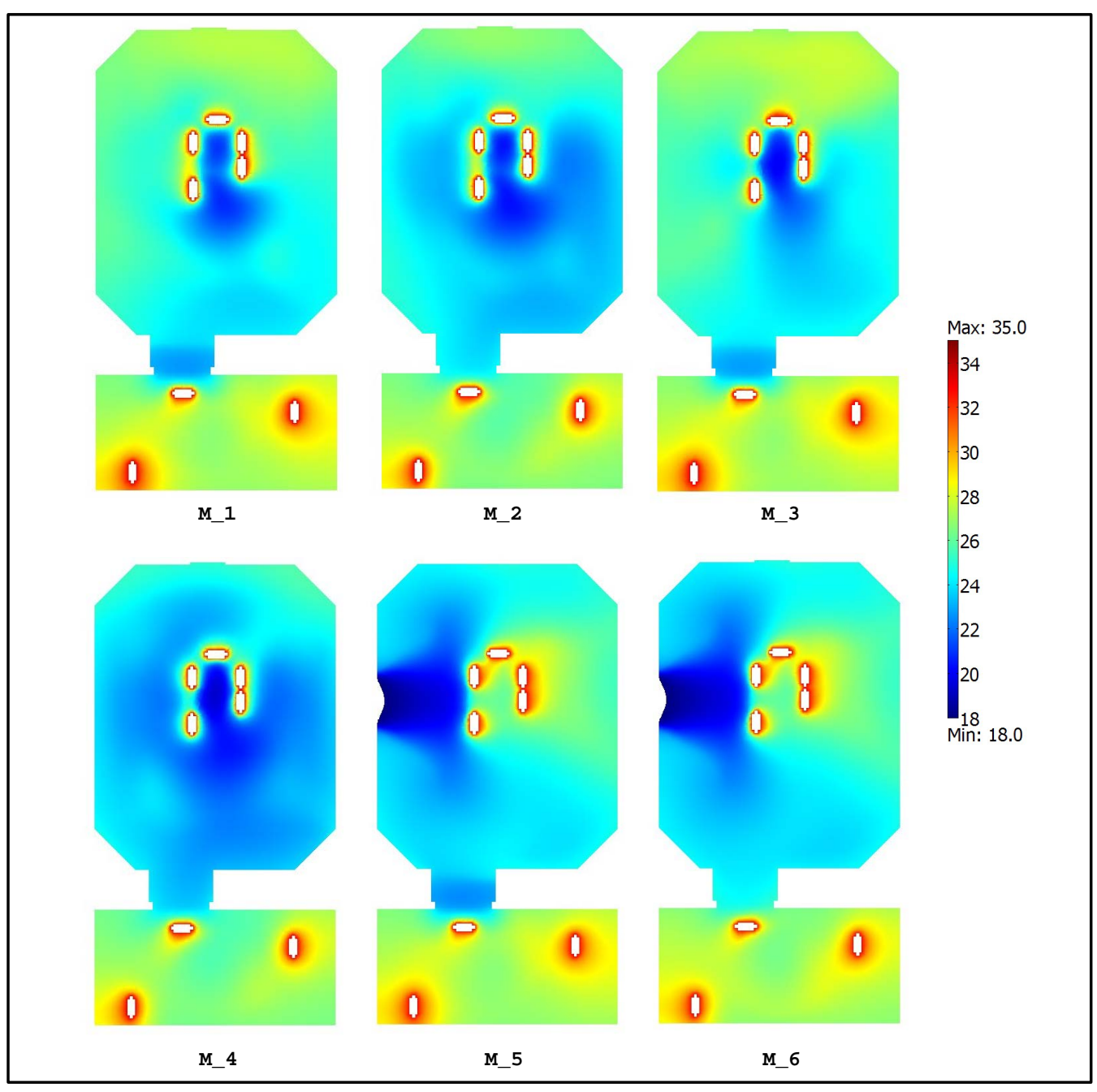

Figure 5. Air temperature field on a horizontal slide (1.4 $\mathrm{m}$ from the floor) for the different ventilation schemes obtained from the six models (from M_1 to M_6).

particle concentration expressed as $\mathrm{CFU} / \mathrm{m}^{3}$ were investigated and the fundamental IAQ indexes, usually applied for air quality assessment, and a quantitative evaluation of ventilation system performance, with regard to contaminant removal and infection risk control, were calculated. These indexes refer to the average values of dependent variables in the different areas into which the OT was divided (i.e. BZ, OZ, PZ and TV). The first investigated parameter for IAQ assessment was the mean age of air $(\tau)$, that quantifies the average lifetime of air at a particular location of the room for a steady airflow achieved. The air age concept expresses the average time for air to travel from a supply inlet area to any location in a forced ventilated room. It was calculated as well as a dependent variable, as explained in the modelling section. Referring to Figure 7, a measure of air freshness can be deduced due to different ventilation schemes: lower values are more favorable. At the inlet opening it was assumed to be zero (100\% fresh). The average value of $\tau$ was computed in the OT different zones and called as $\tau_{Z_{j}}$, where $Z_{j}$ means the generic $j$-zone. Usually these values are quite low. Comparison of these values with the theoretical residence time of air inside the OT (defined as the ratio between the total volume of the room $\left(V_{\mathrm{TV}}, \mathrm{m}^{3}\right)$ and the mass flow rate of incoming ventilating air $\left(V_{\text {vent }}, \mathrm{m}^{3} / \mathrm{s}\right)$ ), shows that the ratio is always higher than 1. This comparison consists in computing the following Air Change Efficiency (ACE) index:

$$
\mathrm{ACE}=\frac{V_{\mathrm{TV}} / \dot{V}_{\text {vent }}}{\tau_{\mathrm{z}_{j}}} \cdot 100
$$

The ACE index measures how effectively ventilation systems replace the air in a room with fresh air. Knowing 


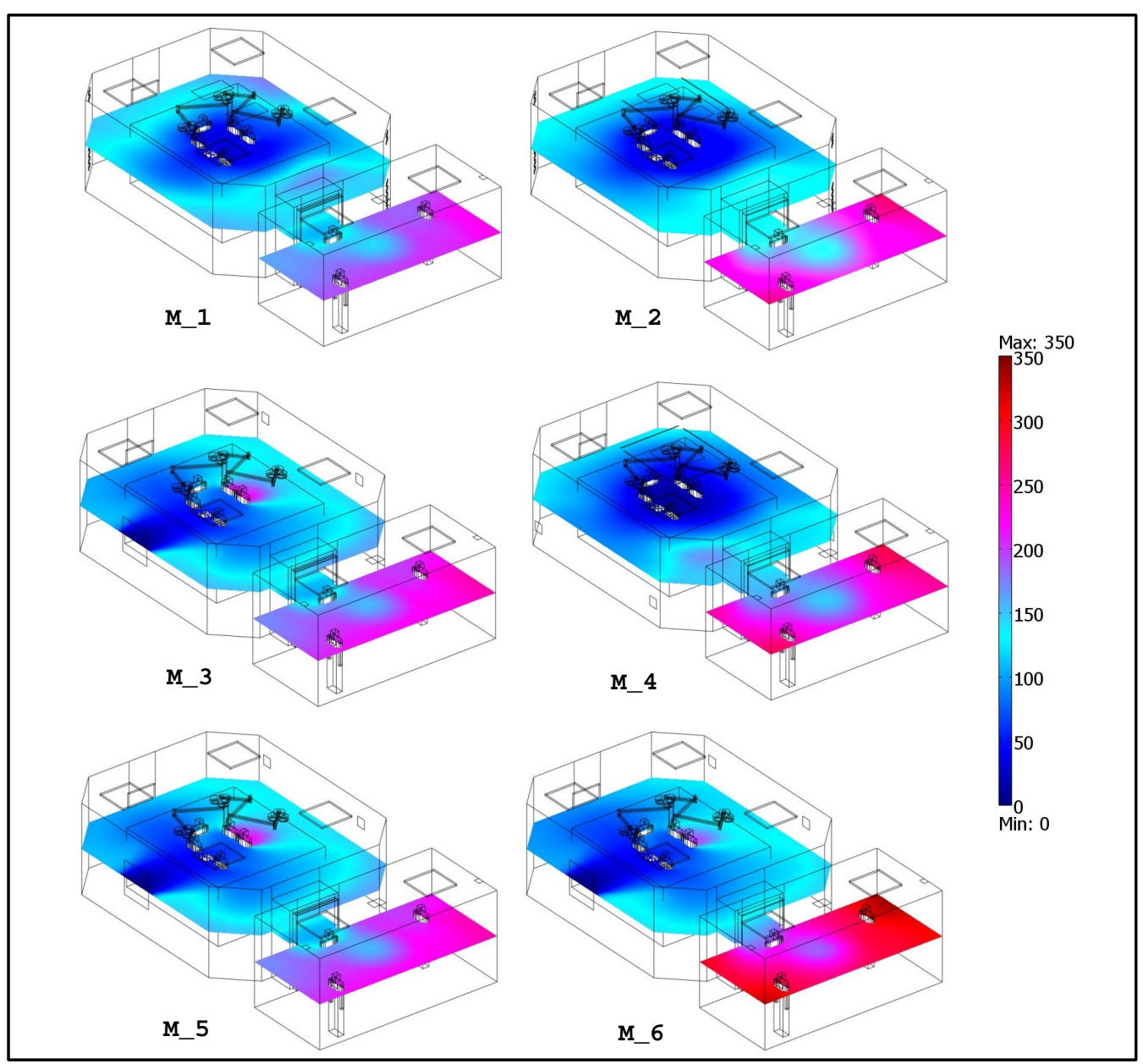

Figure 6. Mean age of air on a horizontal slide (1.4 $\mathrm{m}$ from the floor) for the different ventilation schemes obtained from the six models (from $M \_1$ to $\mathbf{M} \_6$ ).

the concentration field computed for $\mathrm{CO}_{2}$ and particles, the Ventilation Effectiveness (VE) index could be calculated. The VE index measures how quickly a contaminant is removed from an air volume by quantifying the efficiency with which the internal pollutant is diluted or removed. It depends on the air flow patterns, and is expressed as follows:

$$
\mathrm{VE}=\frac{C_{E}-C_{S}}{C_{Z_{j}}-C_{S}}
$$

where $C_{E}$ is the mean value of contaminant concentration (i.e. $\mathrm{CO}_{2}$ and particles) calculated at the air-recovery grilles (Exhaust), $C_{S}$ is the contaminant concentration at the air inlet diffusers (Supply) and $C_{Z_{j}}$ is the mean value of the contaminant concentration in a specific OT zone. Similarly, the Contaminant Removal Effectiveness (CRE) index represents the ratio between the concentration of contaminants at the exhaust point and the mean value of contaminant concentration within a specific zone:

$$
\mathrm{CRE}=\frac{C_{E}}{C_{Z_{j}}}
$$

The VE and CRE indexes were computed using $\mathrm{CO}_{2}$ and particle concentration results. Because the particle concentration value was assumed to be zero at the inlet air diffusers $\left(C_{S}=0\right)$, VE and CRE expressions correspond to each other. Comparing the ACE index obtained for the six models, it can be easily deduced that the proposed ventilation scheme of M_2, M_4 and M_6 produces similar results (Table 6). In particular, the highest 


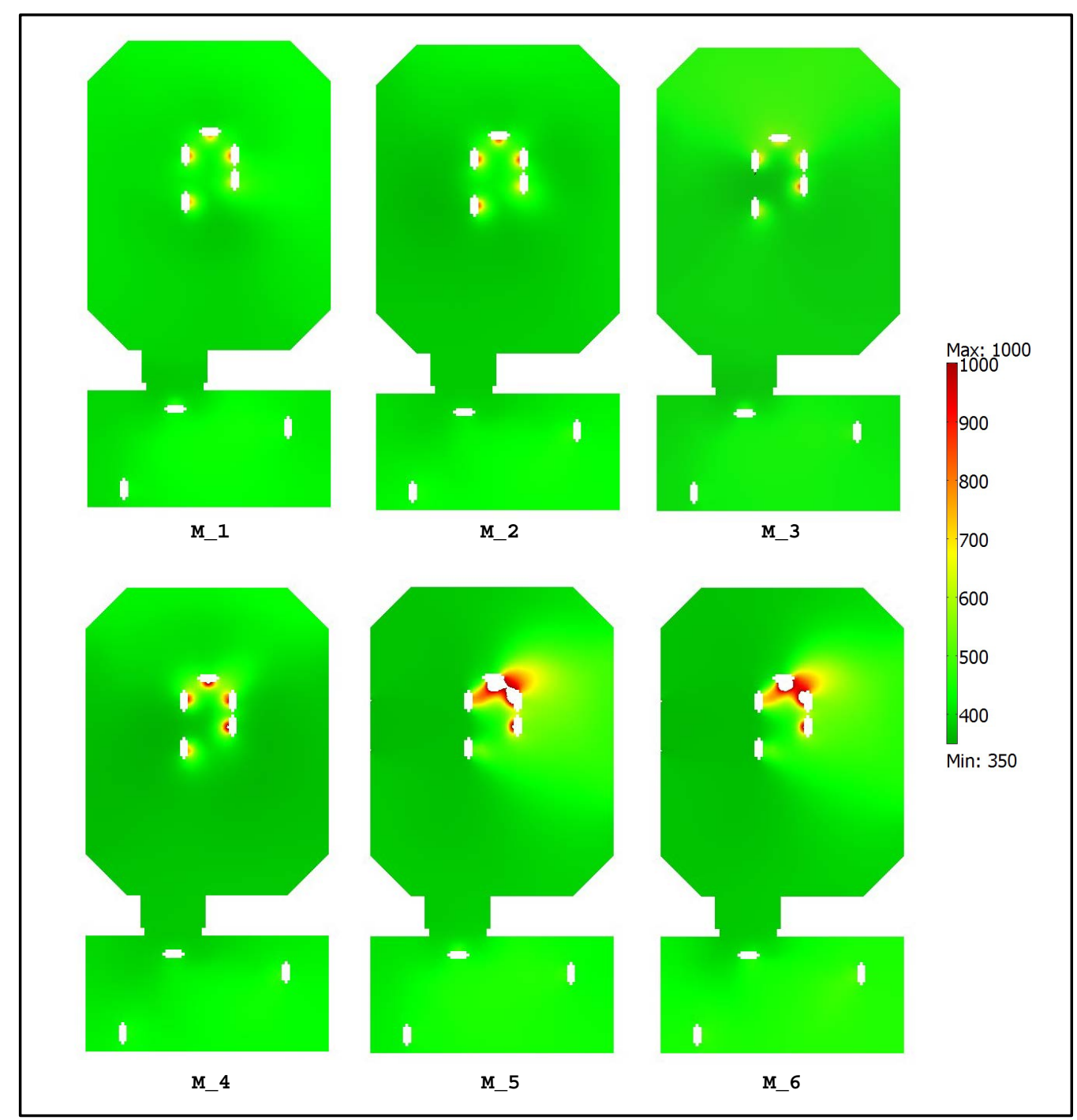

Figure 7. $\mathrm{CO}_{2}$ concentration on a horizontal slide (1.4 $\mathrm{m}$ from the floor) for the different ventilation schemes obtained from the six models (from $\mathrm{M} \_1$ to $\mathrm{M} \_6$ ).

ACE value belongs to M_2 and M_4 with a comparable result of M_6 (Table 6). All these above ventilation schemes do not include the vertical air curtain located at the sliding door: as a matter of fact, its presence seems to cause "short-circuit" of the air flow and local turbulence phenomena in the zone of the door. In M_2 and M_4 results, the effect of air curtain for maintaining the unidirectional downward flow and to prevent the air flow short-circuit between the inlet and outlet air diffusers, is evident. In the two models the vertical air curtain is respectively located at the ceiling supply diffuser along only two sides, corresponding to the underlying sides of the bed in M_2, and along the whole perimeter of the sole central ceiling supply diffuser in $M_{-} 4$, but both of them are not arranged with the vertical air curtain at the sliding door. M_2 and M_4 models provide more similar and comparable results between them, for the IAQ indexes calculated for the different OT zones (Table 6). In particular, the VE and CRE indexes compared to the mean age of air for the BZ and OZ, show better performances and efficacy of the modified ventilation system of M_2 and M_4 models, but also for M_6. Model M_6, also is without the vertical air curtain at the sliding door, but is characterized by a unidirectional horizontal air flow. This is the reason why the M_6 model provides the higher mean air age values for the BZ and OZ, similarly to the M_5 model even if it absolutely provides the highest ones. Considering the PZ and TV the situations inverts (Table 6): M_5 and M_6 models provide similar results of the mean air age and the lowest ones among all the models. 
Table 6. The IAQ indexes for the OT zones and for each ventilation scheme (from M_1 to M_6).

\begin{tabular}{|c|c|c|c|c|c|c|}
\hline Breathing zone (BZ) volume $14.29 \mathrm{~m}^{3}$ & M_1 & M_2 & M_3 & M_4 & M_5 & M_6 \\
\hline $\mathrm{VE}$ & 0.80 & 0.91 & 0.80 & 0.70 & 0.68 & 0.76 \\
\hline CRE & 0.97 & 0.99 & 0.97 & 0.96 & 0.94 & 0.95 \\
\hline$\tau$ & 76.59 & 56.80 & 84.13 & 52.83 & 103.12 & 95.24 \\
\hline PMV & 1.52 & 1.34 & 1.54 & 1.26 & 0.89 & -0.60 \\
\hline PPD (\%) & 52.0 & 42.4 & 52.8 & 38.2 & 21.8 & 12.6 \\
\hline $\mathrm{CFU} / \mathrm{m}^{3}$ & 26.89 & 22.19 & 27.00 & 21.69 & 27.08 & 20.65 \\
\hline Occupied zone (OZ) volume $24.49 \mathrm{~m}^{3}$ & M_1 & M_2 & M_3 & M_4 & M_5 & M_6 \\
\hline VE & 0.75 & 0.82 & 0.84 & 0.67 & 0.89 & 0.99 \\
\hline CRE & 0.96 & 0.97 & 0.97 & 0.95 & 0.98 & 1.00 \\
\hline$\tau$ & 85.56 & 64.53 & 94.07 & 60.82 & 116.09 & 107.56 \\
\hline PMV & 1.68 & 1.54 & 1.71 & 1.46 & 0.93 & -0.49 \\
\hline PPD (\%) & 60.8 & 52.8 & 62.4 & 48.9 & 23.4 & 9.9 \\
\hline $\mathrm{CFU} / \mathrm{m}^{3}$ & 27.20 & 23.64 & 26.42 & 22.88 & 27.04 & 16.93 \\
\hline Peripheral zone (PZ) volume $98.83 \mathrm{~m}^{3}$ & M_1 & M_2 & M_3 & M_4 & M_5 & M_6 \\
\hline VE & 0.98 & 1.34 & 0.90 & 1.11 & 1.76 & 1.97 \\
\hline CRE & 1.00 & 1.03 & 0.98 & 1.01 & 1.07 & 1.08 \\
\hline$\tau$ & 133.08 & 109.58 & 156.40 & 113.17 & 114.66 & 105.69 \\
\hline PMV & 1.49 & 1.33 & 1.52 & 1.23 & 0.89 & -0.64 \\
\hline PPD (\%) & 50.5 & 41.9 & 52.0 & 36.8 & 21.8 & 13.5 \\
\hline $\mathrm{CFU} / \mathrm{m}^{3}$ & 23.77 & 18.72 & 25.43 & 16.92 & 29.12 & 10.84 \\
\hline Total Volume (TV) volume $118.52 \mathrm{~m}^{3}$ & M_1 & M_2 & M_3 & M_4 & M_5 & M_6 \\
\hline VE & 0.92 & 1.18 & 0.89 & 0.97 & 1.46 & 1.63 \\
\hline CRE & 0.99 & 1.02 & 0.98 & 1.00 & 1.05 & 1.06 \\
\hline$\tau$ & 123.03 & 100.08 & 143.26 & 102.16 & 114.76 & 105.90 \\
\hline PMV & 1.45 & 1.30 & 1.49 & 1.22 & 0.83 & -0.67 \\
\hline PPD (\%) & 48.1 & 40.5 & 50.5 & 36.1 & 19.7 & 14.4 \\
\hline $\mathrm{CFU} / \mathrm{m}^{3}$ & 24.44 & 19.70 & 25.59 & 18.12 & 28.64 & 12.08 \\
\hline ACE & 0.59 & 0.72 & 0.50 & 0.70 & 0.63 & 0.68 \\
\hline ADPI (\%) $-1.5 \mathrm{~K}<\mathrm{EDT}<+1 \mathrm{~K}$ & 18 & 38 & 17 & 50 & 23 & 21 \\
\hline
\end{tabular}

Some basic parameters for thermal comfort evaluation were also calculated. They refer to predicted mean vote (PMV) and predicted percentage dissatisfied (PPD) and to the Diffusion Performance Index (ADPI) according to the standards [44] [45]. The ASHRAE Handbook of Fundamentals provides the basic definition of the Air Diffusion Performance Index (ADPI) which statistically relates the space conditions of temperature and air velocity to occupant thermal comfort, underlining that high ADPI values are desirable as they represent a high comfort 
level mainly due to increased probability of good ventilation air mixing.

Considering a chosen number of discrete points in the OT (146 locations for $1<x<5 ; 5<y<10$ and $0.5<z<2.5$ ) and referring to the ASHRAE standard, the ADPI index was computed as the percentage of test points that meets the performance parameters provided by the combination between the Effective Draft Temperature $(-1.5 \mathrm{~K}<\mathrm{EDT}<1.0 \mathrm{~K})$ and air velocity $(U<0.35 \mathrm{~m} / \mathrm{s})$. The EDT is defined as in following:

$$
\mathrm{EDT}=\left(T-T_{\text {set }}\right)-8 \cdot(U-0.15)
$$

As a consequence, when the effective draft temperature is between $-1.5 \mathrm{~K}$ and $+1.0 \mathrm{~K}$ and the air velocity less than $0.35 \mathrm{~m} / \mathrm{s}$, a high percentage of people feel comfortable. Results comparison shows that M_5 and M_6 models guarantee the best thermal comfort conditions for occupants, because their results involve a lower PPD value for all the considered OT zones. Looking at the ADPI index, obtained for the six modified ventilation schemes, M_5 and M_6 models give again the higher ADPI index value and comparable with that of M_6, but the actual lowest values are those provided by M_1 and M_3 models. After all, M_1 and M_3 models have very similar ventilation schemes and both are equipped with the air curtain located at the sliding door.

This same situation is the case for the ACE index results obtained for the six configuration models: for M_2 and M_4 models, this index reaches the highest values and even now comparable with that of M_6; $M \_1$ and M_3 models provide the lower values, similarly to the corresponding ADPI and PPD index values and also to the mean air age both calculated for the TV of the room. In particular, looking at the CFU concentration results for each OT considered zones, the M_2, M_4 models provide the lower values, but M_6 ventilation scheme from this point of view, is the best for BZ, OZ, PZ and then TV. The ventilation schemes of the M_1 and M_3 models, give the higher $\mathrm{CFU} / \mathrm{m}^{3}$ values in all the OT zones.

\section{Discussion}

The many simulations, carried out for studying the ventilation performances due to different ventilation schemes of the real investigated OT, highlight the importance of a correct ventilation plant design for guaranteeing the efficiency and effectiveness of the air flowing for microclimate and thermal comfort (both of patients and surgical staff) control and IAQ levels in the room. The six ventilation schemes studied by means of dedicated CFD simulations, provide results that are in good agreement with those of similar and comparable situations presented in recent literature [15] [17] [46]-[48].

A direct comparison between our obtained results with those provided by literature studies can be made considering the ventilation air flow solutions and configurations, air inlet and return grilles location and the effective air flow schemes. Our study shows that the efficiency and efficacy of the unidirectional vertical air flow, particularly improved with the air curtains application, are in good compliance with those reported in the recent literature [17] [36]. In these studies, different ventilation solutions based on the unidirectional air flow and considering high and low inlet air velocity value, different ACH and exhaust grills location are in any case, the better solution for infection control inside the OTs compared to the horizontal laminar (unidirectional) air flow systems. Our simulation results, obtained for the proposed ventilation schemes that are equipped by unidirectional vertical downward air flow, comply with those pointed out by some important researches on this argument that demonstrate as this kind of ventilation system provides an ultra-clean environment and the better comfort conditions for all the OT zones [12] [13] [15] [18]. Therefore, our investigation shows that the horizontal air flow system, can be an important alternative to the vertical one in the OT only if the supply and return diffusers are located on the opposite site of the same lateral wall and their position is chosen taking into account the location and height of the operating table, medical equipments, instruments tables and other obstructions, compared with the distance of the plenum and air inlet grilles: this result has been widely demonstrated by some authors with important findings [15] [46]-[48] concerning the most significant decrease of post-operative infection obtained with this ventilation solution. Moreover, some authors have also shown that this horizontal laminar (unidirectional) air flow can be a good solution to provide the best thermal comfort conditions to the surgical staff [15] [16] [28] and this effect is that we found improving our proposed ventilation designs with effective air curtain solutions. Results on microclimatic conditions and air flow patterns obtained by our simulations show that the air curtain use at the ceiling inlet air diffuser, is crucial for maintaining the unidirectional downward flow and to prevent the air flow short circuit between the inlet and outlet air diffusers, but also to reduce contaminant concentration in the OT zones. These results are in a good agreement with those of recent researches on the ultrac- 
lean ventilation system performance against airborne infection in a real standard OT [19] [36]. Air temperature values distribution, air flow field and velocity, $\mathrm{CO}_{2}$ concentration levels, pressure scheme in the room, but also all the IAQ and thermal comfort indexes obtained by our simulations, are also in compliance with the current International and Italian standards. Effective air flow pattern, IAQ and thermal comfort in the OT is a very complex problem. The crucial question is the necessity to conciliate several microclimatic and air quality requirements, e.g. the homoiothermy conditions of the patient, avoiding the risk of hypothermia, comfort conditions of the components of the surgical team, correct micro-climatic conditions and to guarantee airborne microbiological components control and contain the infection risk. Results comparison concerning the investigated ventilation schemes, suggests that it is not possible to arrive at an optimum/best ventilation system design, but rather to an optimal one, i.e. in which a good compromise between all the necessary strict requirements is guaranteed. After all, this is exactly what we investigated.

\section{Conclusion}

Numerical simulations of airflow, thermal fields and contaminant concentration distributions were carried out for a real OT under different ventilation schemes for supplying and recovering indoor air. Our investigation provides better understanding of which ventilation scheme can guarantee the best compromise between IAQ levels and comfort requirements under real use conditions of the OT (i.e. incorrect use, mainly due to the door being open during surgical operations). Results confirm the strong effects of a correct ventilation system design and location of the air supply diffusers on compliance of microclimatic conditions with the suggested standard limits, thermal comfort and IAQ levels guarantee and also on satisfactory contaminant removal results, with noticeable low contamination levels at the wound site. A comparison between different proposed ventilation scheme models shows that the closer to the center of the room and larger surface of the air supply diffusers connected with the position of the return grilles, the better the air flow performance is, when provided both by unidirectional vertical and horizontal air flows, especially if the use of air curtains mainly located at the ceiling is considered. High surface of the air supply diffusers combined with air curtains location to control the (both unidirectional vertical and horizontal) air flow direction and correct air recovery grille location, was identified as one of the most important factors in reducing short circuits between inlet and outlet air flows, guaranteeing the efficacy and efficiency of the ventilation system, reducing contaminant concentration in the breathing and occupied/operating zone of the OT and also governing the dispersion of airborne infectious particles. Air flow within the unidirectional regime is advantageous in minimizing the thermal stratification effect, to ensure an adequate washing effect against particulate/contaminant settlement and infection risk at surgical site, guaranteeing better IAQ levels and comfort conditions. Inappropriate positioning of the air curtains combined with the supply diffusers can be detrimental.

\section{Acknowledgements}

The Authors thank Prof. Pietro Vitali (Hospital Hygiene Unit, University Hospital of Parma), Prof. Cesira Pasquarella (Department of Biomedical, Biotechnological and Translational Sciences, University of Parma), Prof. Roberto Albertini (Department of Clinical and Experimental Medicine, Unit of Medical Immunology, University Hospital of Parma) for their crucial cooperation and research support.

\section{References}

[1] ÖNORM-H-6020 (2007) Ventilation and Air Conditioning Plants for Locations for Medical Use-Design, Construction, Operation, Maintenance, Technical and Hygienic Inspections. Austrian Standards Institute/Österreichisches Normungsinstitut $(\mathrm{ON})$, Wien.

[2] VDI-2167-1 (2004) Building Services in Hospitals-Heating, Ventilation and Air-Conditioning. Swiss Guidelines for Hospital. www.eurocode-online.de

[3] NBHF (2004) Building Guidelines for a Surgical Department. The Netherlands Boards for Healthcare Institutions. www.bouwcollege.nl

[4] HTM-03-01 (2007) Heating and Ventilation Systems Health Technical Memorandum 03-01: Specialised Ventilation for Healthcare Premises Part A: Design and Validation. TSO, Edinburgh.

[5] ANSI/ASHRAE-170 (2008) Ventilation of Health Care Facilities. ASHRAE Standards Committee, the ASHRAE Board of Directors, and the American National Standards Institute, USA. www.ashrae.org 
[6] ANSI/ASHRAE-62-1 (2007) Ventilation for Acceptable Indoor Air Quality. ASHRAE, Atlanta.

[7] UNI-EN-ISO-14644-3 (2006) Cleanrooms and Associated Controlled Environments_-Part 3: Test Methods.

[8] UNI-EN-ISO-14644-1 (2006) Cleanrooms and Associated Controlled Environments. Part 1: Classification of Air Cleanliness.

[9] UNI-EN-ISO-14644-2 (2006) Cleanrooms and Associated Controlled Environments Part 2: Specifications for Testing and Monitoring to Prove Continued Compliance with ISO 14644-1.

[10] ISO-21501-4 (2007) Determination of Particle Size Distribution—Single Particle Light Interaction Methods. Part 4: Light Scattering Airborne Particle Counter for Clean Spaces.

[11] UNI-11425 (2011) Surgery Operating Theatre, Ventilation and Air-Conditioning System for Contamination Control (VCCC)—Design, Construction, Commissioning, Qualification, Management and Maintenance. Italy. (In Italian)

[12] Zoon, W.A.C., Loomans, M.G.L.C. and Hensen, J.L.M. (2011) Testing the Effectiveness of Operating Room Ventilation with Regard to Removal of Airborne Bacteria. Building and Environment, 46, 2570-2577. http://dx.doi.org/10.1016/j.buildenv.2011.06.015

[13] Cow, T.T. and Yang, X.Y. (2003) Performance of Ventilation System in a Non-Standard Operating Room. Building and Environment, 38, 1401-1411. http://dx.doi.org/10.1016/S0360-1323(03)00155-0

[14] Méndez, C., San José, J.F., Villafruela, J.M. and Castro, F. (2008) Optimization of a Hospital Room by Means of CFD for More Efficient Ventilation. Energy and Buildings, 40, 849-854. http://dx.doi.org/10.1016/j.enbuild.2007.06.003

[15] Pfost, J.F. (1981) A Re-Evaluation of Laminar Air Flow in Hospital Operating Rooms. ASHRAE Transactions, 87, 729-739.

[16] Kameel, R. and Khalil, E.E. (2003) Experimental and Numerical Investigations of Heat Transfer in Air-Conditioned Operation Theatres. Proceedings of 14th USNCTAM, Symposium on Recent Advances in Three Dimensional Flow Modelling, June 2002, Paper 52.

[17] Ho, S.H., Rosario, L. and Rahman, M.M. (2009) Three-Dimensional Analysis for Hospital Operating Room Thermal Comfort and Contaminant Removal. Applied Thermal Engineering, 29, 2080-2092. http://dx.doi.org/10.1016/j.applthermaleng.2008.10.016

[18] Villafruela, J.M., Castro, F., San José, J.F. and Saint-Martin, J. (2013) Comparison of Air Change Efficiency, Contaminant Removal Effectiveness and Infection Risk as IAQ Indices in Isolation Rooms. Energy and Buildings, 57, 210219. http://dx.doi.org/10.1016/j.enbuild.2012.10.053

[19] Chow, T.T. and Yang, X.Y. (2005) Ventilation Performance in Operating Theatres against Airborne Infection: Numerical Study on an Ultra-Clean System. Journal of Hospital Infection, 59, 138-147. http://dx.doi.org/10.1016/j.jhin.2004.09.006

[20] Chow, T.T. and Wang, J.L. (2012) Dynamic Simulation on Impact of Surgeon Bending Movement on Bacteria Carrying Particles Distribution in Operating Theatre. Building and Environment, 57, 68-80. http://dx.doi.org/10.1016/j.buildenv.2012.04.010

[21] Dong, S.Y., Tu, G.B., Cao, R.G. and Yu, Z.F. (2009) Numerical Study on Effects of Door-Opening on Airflow Patterns and Dynamic Cross-Contamination in an ISO Class 5 Operating Room. Transactions of Tianjin University, 15, 210-215. http://dx.doi.org/10.1007/s12209-009-0037-y

[22] Santa Cruz, A., Guillou, S. and Makhloufi, R. (2007) Effect of Moving Person on Airflow Patterns in a Ventilated Enclosure (Operating Theatre Applications). ITBM RBM (Revue Europeenne de Technologie Biomedicale, In French Language), 28, 49-55. (In French) http://www.sciencedirect.com/science/journal/19590318

[23] Brohus, H., Balling, K.D. and Jeppesen, D. (2006) Influence of Movements on Contaminant Transport in an Operating Room. Indoor Air, 16, 356-372. http://dx.doi.org/10.1111/j.1600-0668.2006.00454.X

[24] Balocco, C., Petrone, G., Cammarata, G., Vitali, P., Albertini, R. and Pasquarella, C.I. (2015) Experimental and Numerical Investigation on Airflow and Climate in a Real Operating Theatre under Effective Use Conditions. International Journal of Ventilation, in Press.

[25] Balocco, C., Petrone, G. and Cammarata, G. (2012) Assessing the Effects of Sliding Doors on an Operating Theatre Climate. Building Simulation: An International Journal, 5, 73-83.

[26] Balocco, C., Petrone, G. and Cammarata, G. (2013) Numerical Multi-Physical Approach for the Assessment of Coupled Heat and Moisture Transfer Combined with People Movements in Historical Buildings. Building Simulation: An International Journal, 7, 289-303.

[27] Yam, R., Yuen, P.L., Yung, R. and Choy, T. (2011) Rethinking Hospital General Ward Ventilation Design Using Computational Fluid Dynamics. Journal of Hospital Infection, 77, 31-36. http://dx.doi.org/10.1016/j.jhin.2010.08.010

[28] Jaramillo, J., Oliva, A., Perez-Segarra, C.D. and Oliet, C. (2008) Application of Air Curtains in Refrigerated Chambers. International Refrigeration and Air Conditioning Conference, Purdue France, 14-17 July 2008, Vol. 2403, 2-8. 
[29] El Harriry, G., Abu Zeid, A. and Khalil, E. (2010) An Investigation of Air Curtains Flows Effects on Heat and Mass Transfer Characteristics in a Cold Room. 46th AIAA/ASME/SAE/ASEE Joint Propulsion Conference \& Exhibit, Nashville, 25-28 July 2010, 2010-6931.

[30] Wang, L.Z. and Zhong, Z.P. (2014) An Approach to Determine Infiltration Characteristics of Building Entrance Equipped with Air Curtains. Energy and Buildings, 75, 312-320. http://dx.doi.org/10.1016/j.enbuild.2014.02.020

[31] Gil-Lopez, T., Castejon-Navas, J., Galvez-Huerta, M.A. and O’Donohoe, P.G. (2014) Energetic, Environmental and Economic Analysis of Climatic Separation by Means of Air Curtains in Cold Storage Rooms. Energy and Buildings, 74, 8-16. http://dx.doi.org/10.1016/j.enbuild.2014.01.026

[32] Chen, Y.G. (2009) Parametric Evaluation of Refrigerated Air Curtains for Thermal Insulation. International Journal of Thermal Sciences, 48, 1988-1996. http://dx.doi.org/10.1016/j.ijthermalsci.2009.03.003

[33] Zhai, Z.Q. and Osborne, A. (2013) Simulation-Based Feasibility Study of Improved Air Conditioning Systems for Hospital Operating Room. Frontiers of Architectural Research, 2, 468-475. http://dx.doi.org/10.1016/j.foar.2013.09.003

[34] Partridge, L.E., Groenhout, K. and Al-Waked, R. (2005) Comparative CFD Analyses of Hospital Ward Ventilation Systems on Reducing Cross Infection Rates. Australian Institute Refrigeration Air Condition Heat Journal, 4, $26-31$.

[35] Loomans, M.G.L.C., van Houdt, W., Lemaire, A.D. and Hensen, J.L.M. (2008) Performance Assessment of an Operating Theatre Design Using CFD Simulation and Tracer Gas Measurements. Indoor and Built Environment, 17, 299312.

[36] Chow, T.T. and Yang, X.Y. (2004) Ventilation Performance in Operating Theatres against Airborne Infection: Review of Research Activities and Practical Guidance. Journal of Hospital Infection, 56, 85-92. http://dx.doi.org/10.1016/j.jhin.2003.09.020

[37] Balocco, C., Petrone, G., Cammarata, G., Vitali, P., Albertini, R. and Pasquarella, C. (2014) Indoor Air Quality in a Real Operating Theatre under Effective Use Conditions. Journal of Biomedical Science and Engineering, 7, 866-883. http://dx.doi.org/10.4236/jbise.2014.711086

[38] ISPESL (2009) Dipartimento Igiene del Lavoro, Linee guida per la definizione degli standard di sicurezza e di igiene ambientale dei reparti operatori. [Department of Occupational Hygiene, Guidelines for the Definition of Safety Standards and Environmental Health Departments Operators (in Italian)]. http://www.ispesl.it/

[39] COMSOL (2012) Multiphysics User’s Guide v. 4.3. Comsol Inc. http://www.comsol.com/

[40] Ignat, L., Pelletier, D. and Ilinca, F. (2000) A Universal Formulation of Two-Equation Models for Adaptive Computation of Turbulent Flows. Computer Methods in Applied Mechanics and Engineering, 189, 1119-1139. http://dx.doi.org/10.1016/S0045-7825(99)00370-9

[41] Launder, B.E. and Spalding, D.B. (1974) The Numerical Computation of Turbulent Flows. Computer Methods in Applied Mechanics and Engineering, 3, 269-289. http://dx.doi.org/10.1016/0045-7825(74)90029-2

[42] Deuflhard, P. (1974) A Modified Newton Method for the Solution of Ill-Conditioned Systems of Nonlinear Equations with Application to Multiple Shooting. Numerische Mathematik, 22, 289-315. http://dx.doi.org/10.1007/BF01406969

[43] Hindmarsh, A.C., Brown, P.N., Grant, K.E., Lee, S.L., Serban, R., Shumaker, D.E. and Woodward, C.S. (2005) SUNDIALS: Suite of Nonlinear and Differential/Algebraic Equation Solvers. Transactions on Mathematical Software ACM (TOMS), 31, 363-396.

[44] UNI EN ISO 7730 (2006) Ergonomics of the Thermal Environment. Analytical Determination and Interpretation of Thermal Comfort Using Calculation of the PMV and PPD Indices and Local Thermal Comfort Criteria. European Committee for Standardization, Brussels.

[45] ANSI ASHRAE Standard 55 (2013) Thermal Environmental Conditions for Human Occupancy. ASHRAE Standards Committee, the ASHRAE Board of Directors, and the American National Standards Institute, USA. www.ashrae.org

[46] Karthikeyan, C.P. and Samuel, A.A. (2008) $\mathrm{CO}_{2}$-Dispersion Studies in an Operation Theatre under Transient Conditions. Energy and Buildings, 40, 231-239. http://dx.doi.org/10.1016/j.enbuild.2007.02.023

[47] Al-Waked, R. (2010) Effect of Ventilation Strategies on Infection Control inside Operating Theatres. Engineering Applications of Computational Fluid Mechanics, 4, 1-16. http://dx.doi.org/10.1080/19942060.2010.11015295

[48] Liu, J.J., Wang, H.D. and Wen, W.Y. (2009) Numerical Simulation on a Horizontal Airflow for Airborne Particles Control in Hospital Operating Room. Building and Environment, 44, 2284-2289.

http://dx.doi.org/10.1016/j.buildenv.2009.03.019 
Scientific Research Publishing (SCIRP) is one of the largest Open Access journal publishers. It is currently publishing more than 200 open access, online, peer-reviewed journals covering a wide range of academic disciplines. SCIRP serves the worldwide academic communities and contributes to the progress and application of science with its publication.

Other selected journals from SCIRP are listed as below. Submit your manuscript to us via either submit@scirp.org or Online Submission Portal.
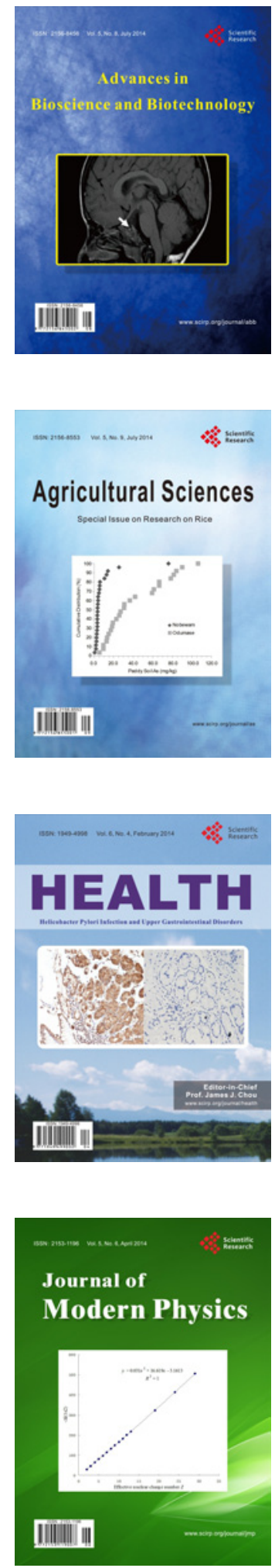
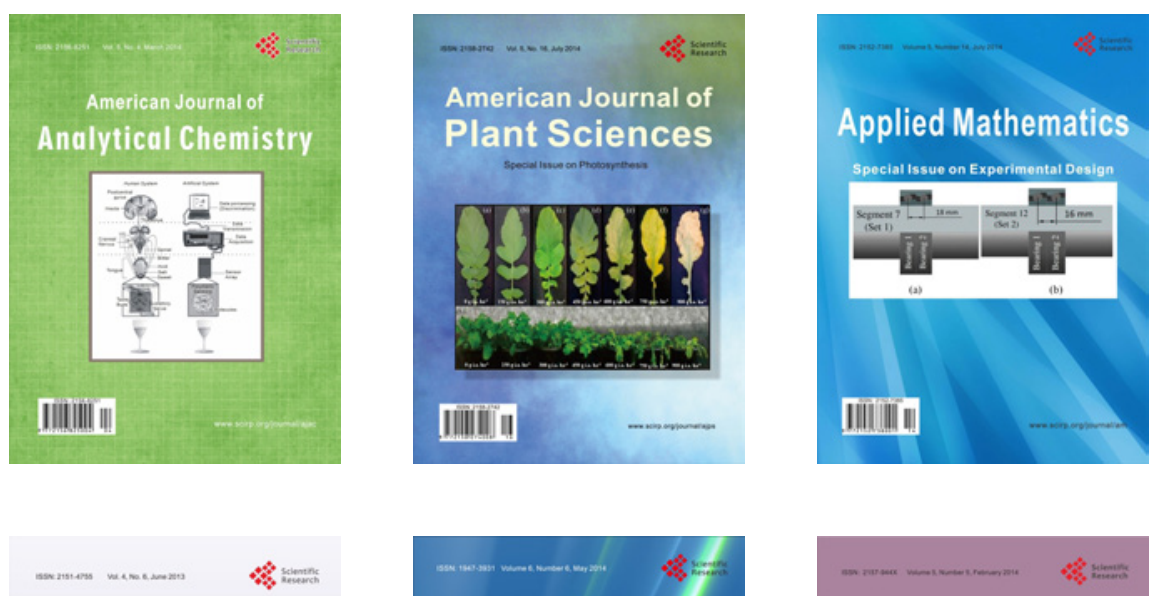

Creative Education
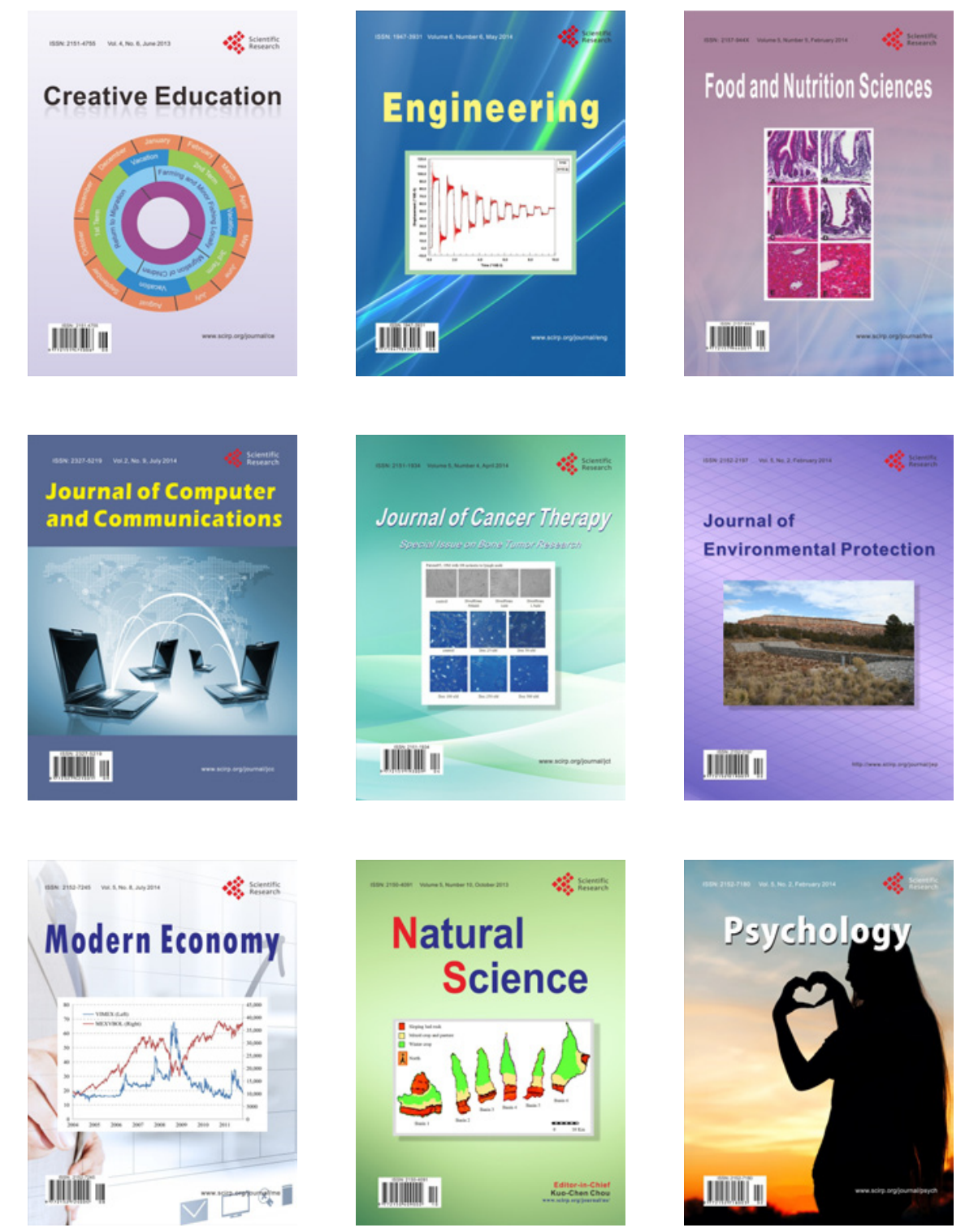